\title{
BMJ Open Associations of reallocating sitting time into standing or stepping with glucose, insulin and insulin sensitivity: a cross-sectional analysis of adults at risk of type 2 diabetes
}

\author{
Charlotte L Edwardson, ${ }^{1,2,3}$ Joe Henson, ${ }^{1,2,3}$ Danielle H Bodicoat, ${ }^{1,3,4}$ \\ Kishan Bakrania, ${ }^{1,2,3,4}$ Kamlesh Khunti, ${ }^{1,3,4}$ Melanie J Davies, ${ }^{1,2,3}$ \\ Thomas Yates ${ }^{1,2,3}$
}

To cite: Edwardson CL, Henson J, Bodicoat DH, et al. Associations of reallocating sitting time into standing or stepping with glucose, insulin and insulin sensitivity: a cross-sectional analysis of adults at risk of type 2 diabetes. BMJ Open 2017;7: e014267. doi:10.1136/ bmjopen-2016-014267

- Prepublication history for this paper is available online. To view these files please visit the journal online (http://dx.doi.org/10.1136/ bmjopen-2016-014267).

Received 12 September 2016 Revised 19 November 2016 Accepted 13 December 2016

CrossMark

For numbered affiliations see end of article.

Correspondence to Dr Charlotte L Edwardson; ce95@le.ac.uk

\section{ABSTRACT}

Objective: To quantify associations between sitting time and glucose, insulin and insulin sensitivity by considering reallocation of time into standing or stepping.

Design: Cross-sectional.

Setting: Leicestershire, UK, 2013.

Participants: Adults aged $30-75$ years at high risk of impaired glucose regulation (IGR) or type 2 diabetes. 435 adults (age $66.8 \pm 7.4$ years; $61.7 \%$ male; $89.2 \%$ white European) were included.

Methods: Participants wore an activPAL3 monitor 24 hours/day for 7 days to capture time spent sitting, standing and stepping. Fasting and 2-hour postchallenge glucose and insulin were assessed; insulin sensitivity was calculated by Homeostasis Model Assessment of Insulin Secretion (HOMA-IS) and Matsuda-Insulin Sensitivity Index (Matsuda-ISI). Isotemporal substitution regression modelling was used to quantify associations of substituting $30 \mathrm{~min}$ of waking sitting time (accumulated in prolonged ( $\geq 30 \mathrm{~min}$ ) or short ( $<30 \mathrm{~min}$ ) bouts) for standing or stepping on glucose regulation and insulin sensitivity. Interaction terms were fitted to assess whether the associations with measures of glucose regulation and insulin sensitivity was modified by sex or IGR status.

Results: After adjustment for confounders, including waist circumference, reallocation of prolonged sitting to short sitting time and to standing was associated with $4 \%$ lower fasting insulin and $4 \%$ higher HOMA-IS; reallocation of prolonged sitting to standing was also associated with a $5 \%$ higher Matsuda-ISI. Reallocation to stepping was associated with 5\% lower 2-hour glucose, $7 \%$ lower fasting insulin, 13\% lower 2-hour insulin and a 9\% and 16\% higher HOMA-IS and Matsuda-ISI, respectively. Reallocation of short sitting time to stepping was associated with $5 \%$ and $10 \%$ lower 2-hour glucose and 2-hour insulin and 12\% higher Matsuda-ISI. Results were not modified by IGR status or sex.

Conclusions: Reallocating a small amount of short or prolonged sitting time with standing or stepping may

\section{Strengths and limitations of this study}

- Sedentary behaviour in epidemiological research is usually assessed using self-reported questions or waist-worn accelerometers which infer sitting posture through lack of movement.

- In this study, the highly accurate activPAL3 monitor, which specifically assesses the postures of sitting, standing and stepping time, was used.

- To the best of our knowledge, this is the first study to examine associations between objectively measured sitting time and insulin sensitivity.

- The sample size is moderate.

- The population used in this study, that is, those identified as being at high risk of developing type 2 diabetes are broadly representative of those referred onto diabetes prevention programmes, therefore having direct relevance for future diabetes prevention.

improve 2-hour glucose, fasting and 2-hour insulin and insulin sensitivity. Findings should be confirmed through prospective and intervention research.

Trial registration number: ISRCTN31392913, Post-results.

\section{INTRODUCTION}

Over the past decade, sedentary behaviour, defined as any waking behaviour characterised by a low energy expenditure while in a sitting or reclining posture ${ }^{1}$ has emerged as a potential independent risk factor for cardiometabolic health, ${ }^{2-5}$ chronic disease ${ }^{6-9}$ and mortality. ${ }^{6}{ }^{10}$ However, epidemiological research to date has either assessed sedentary behaviour using self-reported questions around television viewing, screen time and total sitting time, or used objective measures 
such as waist-worn accelerometers which infer sitting or reclining posture through lack of movement. Determining sedentary behaviour using accelerometers, such as ActiGraph, may result in upright activities with little movement such as standing being misclassified as sedentary, ${ }^{11}$ therefore potentially overestimating time spent in sedentary behaviour. This is important as standing may have potential health benefits. ${ }^{12-15}$

A key factor in improving our understanding of the relationship between sedentary behaviour and health is to use objective devices that directly measure the posture of sitting and can distinguish between seated and upright activity accurately. One such device is the activPAL, which in recent years has increasingly been used in research focused on sedentary behaviour. ${ }^{16}$ This device has shown almost perfect correlation and excellent agreement with direct observation for measuring sitting/lying time, upright time, sitting/lying to upright transitions and detecting reductions in sitting. ${ }^{11}$ 17-19

Isotemporal substitution modelling has previously been used to model the association with health of substituting accelerometer determined sedentary time for light or moderate-to-vigorous physical activity. ${ }^{20-24}$ This type of modelling takes into account that time is finite, therefore spending time in one behaviour results in less time being spent in another. Given the indirect assessment of sitting using waist-worn accelerometers, it is important to repeat these analyses using an objective device that can directly and accurately measure sitting, such as the activPAL. Furthermore, given the suggestion from experimental research that simply standing could benefit health, the activPAL device is able to provide an accurate measure of standing time to enable investigation, through epidemiological data, into the benefits of simply standing; something that most previous studies have been unable to do. To date, only one study ${ }^{25}$ has investigated time reallocation from sitting to standing or stepping measured by the activPAL and associations with health. Healy et $a l^{25}$ in a general population of Australian adults, found that replacing 2 hours of sitting with standing or stepping was beneficially associated with various markers of cardiometabolic health (fasting glucose, triglycerides and high-density lipoprotein cholesterol). However, these findings need to be confirmed and extended by examining other population groups and health markers, such as insulin sensitivity; an important risk factor for chronic disease. Furthermore, it has been suggested in previous research that the way in which sedentary time is accumulated may be important for health. For example, prolonged sedentary behaviour, that is, sitting time that occurs in long periods without interruption, may be more detrimental to health than short bouts of sedentary behaviour. ${ }^{22}$ This also warrants further investigation.

Therefore, the purpose of this study was to expand on previous isotemporal investigations by examining associations between activPAL measured sitting time (split into time accumulated in short $(<30 \mathrm{~min})$ and prolonged $(\geq 30 \mathrm{~min})$ bouts), standing and movement with glucose regulation and measures of insulin sensitivity using isotemporal substitution modelling in a population of adults at risk of type 2 diabetes mellitus (T2DM).

\section{METHODS}

\section{Design and participants}

Participants for this study were part of the Walking Away from Diabetes randomised controlled trial, details of which have been described elsewhere. ${ }^{26}{ }^{27}$ Data collected at the 3-year follow-up visit (2013-2014) were used for this cross-sectional analysis as this was the only time point where participants were asked to wear the activPAL monitor. Adults aged $30-75$ years and identified as being at high risk of impaired glucose regulation (IGR; impaired glucose tolerance and/or impaired fasting glycaemia) or T2DM from general practice databases $(n=10$; range of participants from each practice $=47-127$ ) using a modified version of the automated Leicester Risk Score ${ }^{28}$ that was specifically designed to be administered in primary care were eligible. An automated platform using existing medical records was used to rank individuals for diabetes risk using predefined weighted variables (age, gender, ethnicity, body mass index (BMI), family history of T2DM and use of antihypertensive medication). Individuals scoring within the 90th centile in each practice were invited to take part. Interested individuals returned a reply slip to the research team and a study visit, where participants provided written informed consent, was arranged. Individuals were excluded if they had known T2DM, were taking steroids, were unable to give informed consent and were unable to speak English.

\section{Anthropometric and demographic measures}

Body weight (Tanita TBE 611, Tanita, West Drayton, UK), height and waist circumference (midpoint between the lower costal margin and iliac crest) were measured to the nearest $0.1 \mathrm{~kg}, 0.5$ and $0.5 \mathrm{~cm}$, respectively. Information on smoking status, medication history, family history of disease and ethnicity was obtained by a healthcare professional.

\section{Sitting/lying, standing and stepping measure}

The activPAL3 device (PAL Technologies, Glasgow, UK) is a small thigh-worn monitor which determines body posture (ie, sitting/lying and upright (with and without stepping)), as well as number of steps, step cadence, posture transitions and energy expenditure. The activPAL3 was initialised using the manufacturer's software with default settings. The device was waterproofed with a nitrile sleeve and Hypafix Transparent dressing. Participants were asked to wear the device continuously 24 hours/day for 7 days on the midline anterior aspect of the right thigh secured with a piece of waterproof dressing. 
Glucose and insulin measures

Participants were asked to fast from 22:00 on the evening before the test and to avoid vigorous-intensity physical activity in the preceding 24 hours. Fasting and 2-hour postchallenge glucose and insulin were measured. Fasting and 2-hour insulin were only available on a subsample of participants due to the cessation of bleeding. Glucose samples were measured within a laboratory at the Leicester Royal Infirmary, Leicestershire, UK, using a glucose oxidase method on the Beckman Auto Analyzer (Beckman, High Wycombe, UK). Plasma samples for insulin analysis were frozen within $\mathrm{a}-80^{\circ} \mathrm{C}$ freezer and analysed at the end of data collection using an enzyme immunoassay (80-INSHU-E01.1, E10.1 Alpco Diagnostics 26G Keewaydin Drive, Salem, New Hampshire 03079, USA) at a specialist laboratory by Unilever R\&D, Bedfordshire, UK. Analysis was conducted by individuals blinded to the patients' identity, using stable methodology standardised to external quality assurance reference values. HOMA-IS and Matsuda-ISI were used to estimate insulin sensitivity: ${ }^{29} 30$

$$
\begin{aligned}
\text { HOMA }-I S & =1 / \mathrm{HOMA}-\mathrm{IR}=22.5 /\left(\mathrm{G}_{0} \cdot \mathrm{I}_{0}\right) \\
\text { Matsuda }_{\text {ISI }} & =10000 / \operatorname{sqrt}\left(\mathrm{G}_{0} \cdot \mathrm{I}_{0} \cdot \mathrm{G}_{120} \cdot \mathrm{I}_{120}\right)
\end{aligned}
$$

These models are commonly used indexes of insulin sensitivity in epidemiological research and have been shown to correlate reasonably with gold standard measures of insulin sensitivity (ie, the hyperinsulinaemic-euglycaemic clamp) and/or progression to T2DM. ${ }^{31}{ }^{32}$ Matsuda-ISI is more likely to reflect factors related to insulin release and peripheral insulin resistance whereas HOMA-IS may be a better measure of hepatic insulin resistance. ${ }^{33}$

\section{ActivPAL data processing and reduction}

ActivPAL data were downloaded using the manufacturer's software (activPAL Professional Research Edition, PAL Technologies, Glasgow, UK) and processed using a validated automated algorithm in STATA (StataCorp LP). This has been described in detail elsewhere, ${ }^{34}$ but in brief, the algorithm uses the activPAL event files, to isolate waking hours from 'sleeping' (time in bed), prolonged non-wear periods and invalid data. A valid day was defined as a day with $<95 \%$ spent in any one behaviour (eg, standing or sitting), $>500$ steps and $\geq 10$ hours of waking hours data. Participants were required to have at least four valid days of data to be included in the analysis. Output variables included average time spent sitting/lying (in short bouts $<30 \mathrm{~min}$ and prolonged bouts $\geq 30 \mathrm{~min}$ ), standing and stepping and average waking hours per day.

\section{Statistical analysis}

All statistical analyses were conducted using IBM SPSS Statistics V.22.0. Listwise deletion was used for handling any missing data. Linear regression modelling using an isotemporal substitution approach was used to quantify the association of reallocating $30 \mathrm{~min}$ of sitting/lying (short and prolonged bouts) for $30 \mathrm{~min}$ of standing or stepping on fasting and 2-hour glucose, fasting and 2-hour insulin and insulin sensitivity (HOMA-IS and Matsuda-ISI). Isotemporal substitution has been recommended for use in observational research employing time-based measures of physical activity. ${ }^{35}$

In order to investigate the association between sitting time (accumulated in short and prolonged bouts) and glucose regulation and insulin sensitivity, isotemporal substitution requires that average waking hours (ie, activPAL waking wear hours), time in standing and time stepping are simultaneously entered into a linear regression model; the resulting regression coefficient for standing and stepping represent the association of substituting a given unit of sitting time (which is the missing time segment in the model) into each category, respectively, while keeping waking hours constant. ${ }^{35}$ Each model was further adjusted for age (continuous), sex (male, female), ethnicity (white, non-white), smoking status (never and previous, current), family history of T2DM (yes, no), $\beta$-blocker and statin medication status (yes, no). In addition, results were additionally adjusted for waist circumference to investigate the extent to which adiposity mediated the results. Sensitivity analyses were conducted to investigate whether results were affected if a different measure of adiposity (BMI) was used as a covariate in model 2. Interaction terms were fitted to assess whether the associations with measures of glucose regulation and insulin sensitivity were modified by sex or IGR status; for the purposes of this analysis, IGR was defined as: fasting glucose $\geq 6.0 \mathrm{mmol} / \mathrm{L}$ and/ or 2-hour glucose $\geq 7.8 \mathrm{mmol} / \mathrm{L}$ and/or glycated haemoglobin $\geq 6.0 \%$.

All measures of glucose, insulin and insulin sensitivity displayed non-parametric distributions; therefore, all dependent variables were log-transformed with resulting regression coefficients back transformed; displayed coefficients consequently represent the value by which the dependent variable is multiplied by for a given unit of time in standing or stepping. We display results per 30 min difference as previous experimental research has shown that breaking up prolonged sitting with standing or walking every 30 min elicits significant reductions in glucose and insulin in adults at risk of T2DM. ${ }^{14}$

Assumptions of linearity for each model were verified and multicollinearity was checked using the variance inflation factor (VIF). VIF values in all models were $<5$ indicating that multicollinearity was low. All analyses were two-sided; $\mathrm{p}<0.05$ was considered significant for main effects and $\mathrm{p}<0.1$ was considered significant for interactions.

\section{RESULTS}

A total of 530 participants were asked to wear an activPAL monitor, of which 435 (mean age (SD) 66.8 (7.4) years; $61.7 \%$ male; $89.2 \%$ white European) provided valid data (82\% of total sample) and were 


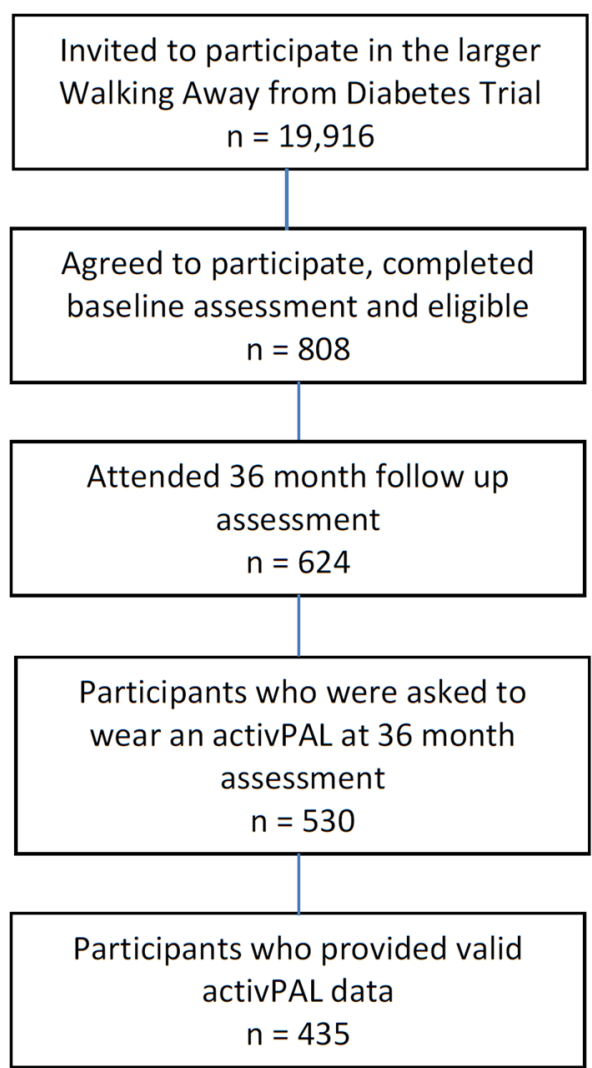

Figure 1 Number of participants approached and included at each stage of the larger study and present analyses.

included in this study (figure 1). Table 1 displays the participant characteristics. The majority of participants $(81 \%)$ provided 7 days of valid activPAL data with a mean (SD) of 9.44 (1.92) hours/day spent sitting, 4.48 (1.49) hours/day standing and 1.68 (0.64) hours/day stepping. Those participants who failed to provide valid activPAL data compared with those who did provide valid activPAL data were more likely to be male $(74 \%$ vs $61 \%)$ and had higher fasting insulin (11.9 vs $10.1 \mathrm{mU} / \mathrm{L}$; $\mathrm{p}=0.016$ ) but there was no difference for age, ethnicity, BMI, waist circumference, fasting and 2-hour glucose and 2-hour insulin (data not in table).

\section{Reallocating prolonged sitting (all time accumulated in bouts $\geq 30 \mathrm{~min}$ )}

Table 2 and figure 2 present the results of the isotemporal substitution. Reallocating $30 \mathrm{~min}$ of prolonged sitting time for short sitting was associated with a lower fasting insulin $(4 \%$ difference $(1-7 \%) ; \mathrm{p}=0.010)$ and higher HOMA-IS (4\% difference $(1-7 \%), \mathrm{p}=0.012)$. Reallocating $30 \mathrm{~min}$ of prolonged sitting time for standing or stepping was associated with a lower fasting insulin $(5 \%$ difference $(2-8 \%), \mathrm{p}=0.001 ; 11 \%$ difference $(5-16 \%), \mathrm{p}=0.001$, respectively) and 2-hour insulin $(6 \%$ difference $(1-10 \%), \mathrm{p}=0.029 ; 15 \%$ difference $(8-22 \%)$, $\mathrm{p}=0.002$, respectively) and a higher HOMA-IS (6\% difference $(2-10 \%), p=0.002 ; 15 \%$ difference $(6-26 \%)$, $\mathrm{p}=0.001$, respectively) and Matsuda-ISI (6\% difference
Table 1 Characteristics of the included participants from Leicestershire, UK (data collected during 2013)

\begin{tabular}{|c|c|}
\hline Characteristics & $(\mathrm{N}=435)$ \\
\hline Age (years) & $66.86 \pm 7.41$ \\
\hline Male (\%) & 61.7 \\
\hline White European (\%) & 89.2 \\
\hline Waist circumference $(\mathrm{cm})$ & $103.79 \pm 12.52$ \\
\hline Body mass index $\left(\mathrm{kg} / \mathrm{m}^{2}\right)$ & $31.47 \pm 5.31$ \\
\hline Currently using $\beta$-blockers (\%) & 20.2 \\
\hline $\begin{array}{l}\text { Currently using lipid lowering } \\
\text { medication (\%) }\end{array}$ & 32.3 \\
\hline Family history of diabetes (\%) & 32.7 \\
\hline Current smokers (\%) & 7.3 \\
\hline $\begin{array}{l}\text { Fasting plasma glucose }(\mathrm{mmol} / \mathrm{L}) \\
(\mathrm{n}=435)\end{array}$ & $5.2(4.8-5.5)$ \\
\hline $\begin{array}{l}\text { 2-hour plasma glucose }(\mathrm{mmol} / \mathrm{L}) \\
(\mathrm{n}=422)\end{array}$ & $5.6(4.7-6.9)$ \\
\hline Fasting insulin (mU/L) $(n=307)$ & $9.0(6.3-13.1)$ \\
\hline 2-hour insulin (mU/L) ( $n=266)$ & $44.0(23.7-79.2)$ \\
\hline \multicolumn{2}{|l|}{ ActivPAL variables } \\
\hline \multicolumn{2}{|l|}{ Days of valid wear (\%) } \\
\hline 4 days & 3.2 \\
\hline 5 days & 4.3 \\
\hline 6 days & 11.9 \\
\hline 7 days & 80.6 \\
\hline Average waking wear (hours/day) & $15.59 \pm 1.26$ \\
\hline Average sitting/lying time (hours/day) & $9.44 \pm 1.92$ \\
\hline $\begin{array}{l}\text { Average short ( }<30 \mathrm{~min} \text { ) bouts of } \\
\text { sitting/lying time (hours/day) }\end{array}$ & $4.19 \pm 1.23$ \\
\hline $\begin{array}{l}\text { Average prolonged ( } \geq 30 \mathrm{~min} \text { ) bouts } \\
\text { of sitting/lying time (hours/day) }\end{array}$ & $5.24 \pm 1.99$ \\
\hline Average standing (hours/day) & $4.48 \pm 1.49$ \\
\hline Average stepping (hours/day) & $1.68 \pm 0.64$ \\
\hline
\end{tabular}

(1-11\%), $\mathrm{p}=0.018 ; 22 \%$ difference $(9-35 \%), \mathrm{p}<0.001$, respectively). Furthermore, reallocating $30 \mathrm{~min}$ of prolonged sitting time for stepping was also associated with a lower fasting (2\% difference $(1-3 \%), \mathrm{p}=0.046)$ and 2 -hour glucose $(6 \%$ difference $(3-8 \%), p=0.001)$. No associations were observed for any other glucose and insulin measures $(p>0.05)$. After adjusting for waist circumference, some associations were attenuated but reallocating prolonged sitting for standing or stepping was no longer significantly associated with 2-hour insulin and fasting glucose, respectively (table 2 and figure 2 ).

\section{Reallocating short sitting (all time accumulated in bouts $<30 \mathrm{~min}$ )}

No associations with glucose, insulin and insulin sensitivity were observed for reallocating $30 \mathrm{~min}$ of short sitting for standing. Reallocating $30 \mathrm{~min}$ of short sitting time for stepping was associated with lower 2-hour glucose (5\% difference $(3-8 \%), \mathrm{p}<0.001)$, fasting insulin $(7 \%$ difference $(2-12 \%), \mathrm{p}=0.006)$ and 2-hour insulin $(13 \%$ difference $(7-19 \%), \mathrm{p}=0.003)$ and a higher HOMA-IS 
Table 2 Associations of reallocating $30 \mathrm{~min}$ of prolonged and short sitting/lying for standing or stepping with measures of glucose regulation and insulin sensitivity

\begin{tabular}{|c|c|c|c|c|c|c|c|c|c|c|c|}
\hline & $\mathbf{n}$ & $\begin{array}{l}\text { Prolonged ST } \\
\text { to short ST }\end{array}$ & $p$ Value & $\begin{array}{l}\text { Prolonged ST } \\
\text { to standing }\end{array}$ & $p$ Value & $\begin{array}{l}\text { Prolonged ST } \\
\text { to stepping }\end{array}$ & $p$ Value & $\begin{array}{l}\text { Short ST } \\
\text { to standing }\end{array}$ & $p$ Value & $\begin{array}{l}\text { Short ST } \\
\text { to stepping }\end{array}$ & $p$ Value \\
\hline \multicolumn{12}{|c|}{ Model 1 (coefficient $(95 \% \mathrm{Cl}$ ) } \\
\hline Fasting glucose & 435 & $\begin{array}{l}1.00 \\
(0.99 \text { to } 1.00)\end{array}$ & 0.178 & $\begin{array}{l}1.00 \\
\text { (0.99 to } 1.01)\end{array}$ & 0.395 & $\begin{array}{l}0.98 \\
(0.97 \text { to } 0.99)\end{array}$ & 0.046 & $\begin{array}{l}1.00 \\
(0.99 \text { to } 1.01)\end{array}$ & 0.781 & $\begin{array}{l}0.99 \\
(0.98 \text { to } 1.00)\end{array}$ & 0.082 \\
\hline 2-hour glucose & 422 & $\begin{array}{l}0.99 \\
(0.97 \text { to } 1.01)\end{array}$ & 0.235 & $\begin{array}{l}1.00 \\
(0.98 \text { to } 1.01)\end{array}$ & 0.460 & $\begin{array}{l}0.94 \\
(0.92 \text { to } 0.97)\end{array}$ & 0.001 & $\begin{array}{l}1.00 \\
(0.99 \text { to } 1.00)\end{array}$ & 0.429 & $\begin{array}{l}0.95 \\
(0.92 \text { to } 0.97)\end{array}$ & $<0.001$ \\
\hline Fasting insulin & 307 & $\begin{array}{l}0.96 \\
(0.93 \text { to } 0.99)\end{array}$ & 0.010 & $\begin{array}{l}0.95 \\
(0.92 \text { to } 0.98)\end{array}$ & 0.001 & $\begin{array}{l}0.89 \\
(0.84 \text { to } 0.95)\end{array}$ & 0.001 & $\begin{array}{l}0.98 \\
(0.95 \text { to } 1.01)\end{array}$ & 0.204 & $\begin{array}{l}0.93 \\
(0.88 \text { to } 0.98)\end{array}$ & 0.006 \\
\hline 2-hour insulin & 266 & $\begin{array}{l}0.97 \\
(0.92 \text { to } 1.02)\end{array}$ & 0.147 & $\begin{array}{l}0.94 \\
(0.90 \text { to } 0.99)\end{array}$ & 0.029 & $\begin{array}{l}0.85 \\
(0.78 \text { to } 0.92)\end{array}$ & 0.002 & $\begin{array}{l}0.98 \\
(0.94 \text { to } 1.02)\end{array}$ & 0.258 & $\begin{array}{l}0.87 \\
(0.81 \text { to } 0.93)\end{array}$ & 0.003 \\
\hline HOMA-IS & 307 & $\begin{array}{l}1.04 \\
\text { (1.01 to } 1.07)\end{array}$ & 0.012 & $\begin{array}{l}1.06 \\
(1.02 \text { to } 1.10)\end{array}$ & 0.002 & $\begin{array}{l}1.15 \\
\text { (1.06 to } 1.26)\end{array}$ & 0.001 & $\begin{array}{l}1.02 \\
(0.99 \text { to } 1.05)\end{array}$ & 0.284 & $\begin{array}{l}1.10 \\
(1.03 \text { to } 1.17)\end{array}$ & 0.004 \\
\hline Matsuda-ISI & 264 & $\begin{array}{l}1.03 \\
(0.99 \text { to } 1.07)\end{array}$ & 0.100 & $\begin{array}{l}1.06 \\
(1.01 \text { to } 1.11)\end{array}$ & 0.018 & $\begin{array}{l}1.22 \\
(1.09 \text { to } 1.35)\end{array}$ & $<0.001$ & $\begin{array}{l}1.02 \\
\text { (0.99 to } 1.06)\end{array}$ & 0.239 & $\begin{array}{l}1.17 \\
\text { (1.07 to } 1.27)\end{array}$ & $<0.001$ \\
\hline \multicolumn{12}{|c|}{ Model 2 (coefficient $(95 \% \mathrm{Cl}$ ) } \\
\hline Fasting glucose & 435 & $\begin{array}{l}1.00 \\
\text { (0.99 to } 1.01)\end{array}$ & 0.188 & $\begin{array}{l}1.00 \\
\text { (0.99 to } 1.01)\end{array}$ & 0.611 & $\begin{array}{l}0.99 \\
\text { (0.98 to } 1.00)\end{array}$ & 0.159 & $\begin{array}{l}1.00 \\
(0.99 \text { to } 1.01)\end{array}$ & 0.866 & $\begin{array}{l}1.00 \\
(0.98 \text { to } 1.01)\end{array}$ & 0.261 \\
\hline 2-hour glucose & 422 & $\begin{array}{l}0.99 \\
\text { (0.97 to } 1.01)\end{array}$ & 0.236 & $\begin{array}{l}1.00 \\
(0.98 \text { to } 1.02)\end{array}$ & 0.602 & $\begin{array}{l}0.95 \\
(0.92 \text { to } 0.98)\end{array}$ & 0.002 & $\begin{array}{l}1.00 \\
(0.99 \text { to } 1.00)\end{array}$ & 0.417 & $\begin{array}{l}0.95 \\
(0.93 \text { to } 0.98)\end{array}$ & 0.001 \\
\hline Fasting insulin & 307 & $\begin{array}{l}0.96 \\
(0.94 \text { to } 0.98)\end{array}$ & 0.013 & $\begin{array}{l}0.96 \\
(0.93 \text { to } 0.99)\end{array}$ & 0.028 & $\begin{array}{l}0.93 \\
(0.88 \text { to } 0.98)\end{array}$ & 0.007 & $\begin{array}{l}0.99 \\
(0.96 \text { to } 1.02)\end{array}$ & 0.532 & $\begin{array}{l}0.96 \\
(0.92 \text { to } 1.00)\end{array}$ & 0.173 \\
\hline 2-hour insulin & 266 & $\begin{array}{l}0.97 \\
\text { (0.92 to } 1.02)\end{array}$ & 0.158 & $\begin{array}{l}0.95 \\
\text { (0.91 to } 1.00)\end{array}$ & 0.052 & $\begin{array}{l}0.87 \\
(0.80 \text { to } 0.94)\end{array}$ & 0.011 & $\begin{array}{l}0.99 \\
(0.95 \text { to } 1.03)\end{array}$ & 0.441 & $\begin{array}{l}0.90 \\
(0.83 \text { to } 0.98)\end{array}$ & 0.021 \\
\hline HOMA-IS & 307 & $\begin{array}{l}1.04 \\
(1.01 \text { to } 1.07)\end{array}$ & 0.016 & $\begin{array}{l}1.04 \\
(1.01 \text { to } 1.07)\end{array}$ & 0.012 & $\begin{array}{l}1.09 \\
(1.01 \text { to } 1.17)\end{array}$ & 0.024 & $\begin{array}{l}1.00 \\
(0.97 \text { to } 1.03)\end{array}$ & 0.680 & $\begin{array}{l}1.05 \\
\text { (0.99 to } 1.11)\end{array}$ & 0.143 \\
\hline Matsuda-ISI & 264 & $\begin{array}{l}1.03 \\
(0.98 \text { to } 1.08)\end{array}$ & 0.116 & $\begin{array}{l}1.05 \\
\text { (1.01 to } 1.09)\end{array}$ & 0.042 & $\begin{array}{l}1.16 \\
(1.05 \text { to } 1.28)\end{array}$ & 0.004 & $\begin{array}{l}1.01 \\
(0.96 \text { to } 1.05)\end{array}$ & 0.515 & $\begin{array}{l}1.12 \\
(1.03 \text { to } 1.22)\end{array}$ & 0.008 \\
\hline
\end{tabular}

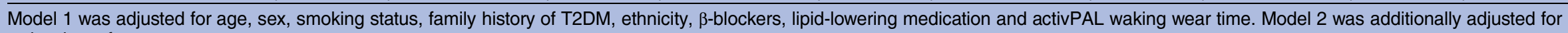
waist circumference.

Bolded values indicate statistically significant $(p<0.05)$ associations.

ST, sitting time. 


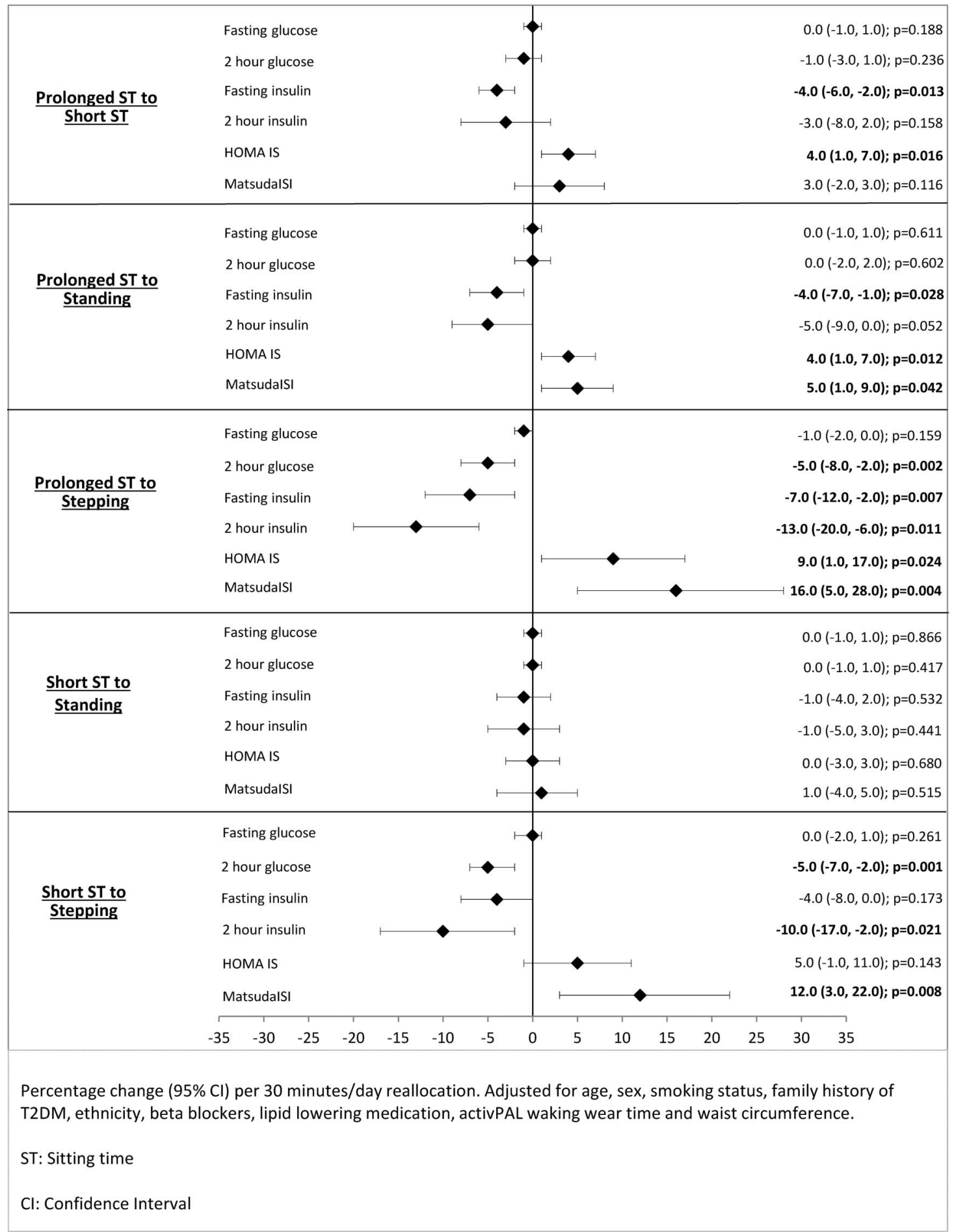

Figure 2 Percentage change in glucose regulation and insulin sensitivity measures of $30 \mathrm{~min} /$ day reallocations of mean prolonged sitting/lying coinciding with equivalent increases in short sitting/lying, standing or stepping time and mean short sitting time with equivalent increases in standing and stepping time. T2DM, type 2 diabetes mellitus.

(10\% difference $(3-17 \%), p=0.004)$ and Matsuda-ISI (17\% difference $(7-27 \%), \mathrm{p}<0.001)$. No associations were observed for any other glucose and insulin measures. After adjusting for waist circumference, associations were attenuated and no longer significant for fasting insulin and HOMA-IS (table 2 and figure 2).
Given the high correlation between the waist circumference and BMI $(\mathrm{r}=0.84, \mathrm{p}<0.001)$ results reported above were unaffected if BMI, rather than waist circumference was used in model 2.

There was no interaction by sex or IGR status for any measure $(\mathrm{p}>0.1$ for all $)$. 


\section{DISCUSSION}

This unique study modelled the association of reallocating time spent sitting (accumulated in short and prolonged bouts) to standing or stepping, measured with a robust objective assessment of posture, on associations with glucose, insulin and insulin sensitivity. Our results demonstrate that reallocating a small amount of sitting time into time spent standing or walking is associated better insulin sensitivity in a population who are potentially at high risk of developing T2DM. Importantly, these associations were observed when reallocating time in prolonged sitting to standing or stepping or reallocating time in short sitting to stepping. Stronger associations were observed for stepping and no associations were observed for reallocating short sitting to standing.

Only one other recently published epidemiological study has investigated the association of replacing objectively assessed sitting with standing or stepping on associations with glucose where small associations were reported for fasting glucose. ${ }^{25}$ Our study extends this initial work by investigating differences between short and long bouts of sitting time, using a cohort with a high risk of T2DM and employing measures of insulin sensitivity. We observed that reallocating $30 \mathrm{~min}$ of prolonged sitting for short sitting, standing and stepping time had beneficial associations with HOMA-IS (4-9\% lower). Additionally, we also found that reallocating $30 \mathrm{~min}$ of both short (12\% higher) and prolonged sitting to standing $(5 \%$ higher) and stepping (16\% higher) was associated with beneficial impacts on Matsuda-ISI, a finding which is consistent with previous studies measuring sedentary behaviour indirectly with waist-worn accelerometers. ${ }^{21} 23$ Both Yates and colleagues and Buman and colleagues found that reallocating time in sedentary behaviour to light intensity physical activity was associated with an increase in Matsuda-ISI and a decrease in fasting insulin and HOMA- $\beta$ and an increase in HOMA-S, respectively. Furthermore, these studies observed stronger associations when reallocating sedentary time to moderate-to-vigorous physical activity, a finding broadly in line with the present study indicating that a higher intensity activity (ie, stepping) produced stronger beneficial associations than standing. Nevertheless, breaking up sitting time by standing more may be a more amenable target and act as a first 'behavioural' step for certain populations such as older adults or those at risk of T2DM.

Previous research has suggested that the way in which sedentary time is accumulated may also be important for health. ${ }^{20} 22$ We examined time spent sitting accumulated in bouts $<30 \mathrm{~min}$ (short) and $\geq 30 \mathrm{~min}$ (prolonged) and investigated whether the associations for reallocating time to standing or stepping differed by sitting time accumulation (ie, short vs prolonged bouts). Our findings reinforce previous studies ${ }^{20} 22$ by demonstrating that reallocating time from prolonged sitting to short sitting may be beneficial, but reallocating time from short sitting to very light activity such as standing may not be enough of a stimulus to result in health benefits.
The findings from the current study also support previous experimental research showing that breaking up prolonged sitting with walking (light or moderate) improves measures of insulin sensitivity acutely, ${ }^{13} 14$ 36-38 with standing breaks also found to be beneficial in those with a high risk of T2DM. ${ }^{14}$ For example, in a similar population of at-risk adults, Henson and colleagues demonstrated that breaking up sitting every $30 \mathrm{~min}$ with 5 min of either standing or light walking significantly reduced postprandial glucose and insulin area under the curve across a 7.5-hour day. ${ }^{14}$ However, the acute nature of these studies prohibits inferences about longer term effects on health. Only a small number of studies have examined longer term reductions in sedentary behaviour. $^{39} 40$ Aadahl et $a \ell^{39}$ reported improvements in fasting insulin and HOMA-IS following a 6-month intervention to reduce sitting time. In contrast however, Kozey-Keadle et $a l,{ }^{40}$ in a small 12-week pilot study, only observed increases in insulin sensitivity when a reduction in sitting time was accompanied by moderate exercise.

The exact mechanisms by which reducing sitting through standing and walking impacts on markers of dysglycaemia are unclear. Moderate-to-vigorous intensity physical activity has been shown to enhance insulinstimulated and contraction-stimulated glucose transport capacity, the product of which is an increase in the expression of skeletal muscle glucose transporter 4 (GLUT4). ${ }^{41}$ However, it is unknown to what extent and through what mechanisms lower stimulus activity such as standing or light walking influence the translocation and turnover of GLUT4 within muscle cells, although pilot work suggests that breaking prolonged sitting with light walking upregulates muscle contraction-stimulated, AMPK-mediated glucose uptake pathways. ${ }^{42}$ This needs to be further investigated in future experimental studies.

Our study has several strengths. Unlike the majority of previous studies, sitting time was measured objectively using a device that directly assesses different postures, that is, sitting, standing and walking. We included robust measures of fasting and 2-hour glucose and insulin which enabled us to examine novel associations with insulin sensitivity. Finally, our unique cohort of individuals identified as being at increased risk of developing T2DM are broadly representative of those referred onto diabetes prevention programmes, therefore having direct relevance for future diabetes prevention. Although our sample size was reasonable, considerably fewer individuals $(\sim 100)$ provided measures of insulin sensitivity compared with glucose measures due to insufficient volumes of blood. The cross-sectional design of this study limits the ability to make causal inferences and the use of isotemporal substitution modelling does not reflect actual behavioural time reallocation within this cohort. Our findings need to be confirmed through prospective and intervention research that can demonstrate actual change in behaviour.

In conclusion, this study provides novel evidence for the potential benefits on glucose, insulin and insulin sensitivity when substituting small amounts of sitting 
time for standing and greater benefits may be achieved when substituting small amounts of sitting time for stepping. However, results should be viewed with caution given the study design and need to be replicated with intervention studies.

\section{Author affiliations}

${ }^{1}$ Diabetes Research Centre, University of Leicester, Leicester, UK

${ }^{2}$ NIHR Leicester-Loughborough Diet, Lifestyle and Physical Activity

Biomedical Research Unit, Leicester, UK

${ }^{3}$ Leicester Diabetes Centre, Leicester General Hospital, University Hospitals of Leicester, Leicester, UK

${ }^{4}$ NIHR Collaboration for Leadership in Applied Health Research and Care East Midlands, Leicester, UK

Acknowledgements The analysis reported in this paper was supported by the NIHR Diet, Lifestyle and Physical Activity Biomedical Research Unit based at University Hospitals of Leicester and Loughborough University, the National Institute for Health Research Collaboration for Leadership in Applied Health Research and Care-East Midlands (NIHR CLAHRC-EM) and the Leicester Clinical Trials Unit.

Disclaimer The views expressed are those of the authors and not necessarily those of the NHS, the NIHR or the Department of Health.

Contributors CLE had the original idea for the analysis and wrote the first draft of the manuscript. DHB and KB contributed to data processing. JH analysed the data. All authors contributed to the interpretation of the data, reviewed/edited the manuscript and approved the final manuscript.

Funding The Walking Away trial was funded by the National Institute for Health Research (NIHR) Collaboration for Leadership in Applied Health Research and Care for Leicestershire, Northamptonshire and Rutland. Analysis of fasting and 2-hour insulin was funded by Unilever R\&D, UK.

Competing interests None declared.

Ethics approval Ethical approval was obtained from the Nottingham Research Ethics Committee, UK.

Provenance and peer review Not commissioned; externally peer reviewed.

Data sharing statement No additional data are available.

Open Access This is an Open Access article distributed in accordance with the Creative Commons Attribution Non Commercial (CC BY-NC 4.0) license, which permits others to distribute, remix, adapt, build upon this work noncommercially, and license their derivative works on different terms, provided the original work is properly cited and the use is non-commercial. See: http:// creativecommons.org/licenses/by-nc/4.0/

\section{REFERENCES}

1. Sedentary Behaviour Research Network. Letter to the editor: standardized use of the terms "sedentary" and "sedentary behaviours". Appl Physiol Nutr Metab 2012;37:540-2.

2. Brocklebank LA, Falconer CL, Page AS, et al. Accelerometer-measured sedentary time and cardiometabolic biomarkers: a systematic review. Prev Med 2015;76:92-102.

3. Edwardson CL, Gorely T, Davies MJ, et al. Association of sedentary behaviour with metabolic syndrome: a meta-analysis. PLOS ONE 2012; 7:e34916

4. Henson J, Yates T, Biddle SJH, et al. Associations of objectively measured sedentary behaviour and physical activity with markers of cardiometabolic health. Diabetologia 2013;56:1012-20.

5. Healy GN, Matthews CE, Dunstan DW, et al. Sedentary time and cardio-metabolic biomarkers in US adults: NHANES 2003-06. Eur Heart J 2011;32:590-7.

6. Wilmot EG, Edwardson CL, Achana FA, et al. Sedentary time in adults and the association with diabetes, cardiovascular disease and death: systematic review and meta-analysis. Diabetologia 2012;55:2895-905

7. de Rezende LF, Rey-López JP, Matsudo VK, et al. Sedentary behavior and health outcomes among older adults: a systematic review. BMC Public Health 2014;14:333.
8. Thorp AA, Owen N, Neuhaus M, et al. Sedentary behaviors and subsequent health outcomes in adults a systematic review of longitudinal studies 1996-2011. Am J Prev Med 2011;41:207-15

9. Shen $\mathrm{D}$, Mao W, Liu T, et al. Sedentary behavior and incident cancer: a meta-analysis of prospective studies. PLOS ONE 2014;9: e105709.

10. Biswas A, Oh PI, Faulkner GE, et al. Sedentary time and its association with risk for disease incidence, mortality, and hospitalization in adults: a systematic review and meta-analysis. Ann Intern Med 2015;162:123-32.

11. Kozey-Keadle S, Libertine A, Staudenmayer J, et al. The feasibility of reducing and measuring sedentary time among overweight, non-exercising office workers. $J$ Obes 2012;2012:282303

12. Buckley JP, Mellor DD, Morris M, et al. Standing-based office work shows encouraging signs of attenuating post-prandial glycaemic excursion. Occup Environ Med 2014;71:109-11.

13. Thorp AA, Kingwell BA, Sethi $P$, et al. Alternating bouts of sitting and standing attenuate postprandial glucose responses. Med Sci Sports Exerc 2014:46:2053-61.

14. Henson J, Davies MJ, Bodicoat DH, et al. Breaking up prolonged sitting with standing or walking attenuates the postprandial metabolic response in postmenopausal women: a randomized acute study. Diabetes Care 2016;39:130-8.

15. Zeigler ZS, Mullane S, Crespo NC, et al. Effects of standing and light-intensity activity on ambulatory blood pressure. Med Sci Sports Exerc 2016;48:175-81.

16. Edwardson $\mathrm{CL}$, Bodicoat D, Winkler EA, et al. Considerations when using the activPAL monitor in field based research with adult populations. J Sport Health Sci 2016. In press. doi:10.1016/j. jshs.2016.02.002

17. Grant PM, Ryan CG, Tigbe WW, et al. The validation of a novel activity monitor in the measurement of posture and motion during everyday activities. Br J Sports Med 2006;40:992-7.

18. Kozey-Keadle S, Libertine A, Lyden $\mathrm{K}$, et al. Validation of wearable monitors for assessing sedentary behavior. Med Sci Sports Exerc 2011;43:1561-7.

19. Lyden K, Kozey-Keadle SL, Staudenmayer JW, et al. Validity of two wearable monitors to estimate breaks from sedentary time. Med Sci Sports Exerc 2012;44:2243-52.

20. Falconer CL, Page AS, Andrews RC, et al. The potential impact of displacing sedentary time in adults with type 2 diabetes. Med Sci Sports Exerc 2015;47:2070-5.

21. Yates T, Henson J, Edwardson C, et al. Objectively measured sedentary time and associations with insulin sensitivity: Importance of reallocating sedentary time to physical activity. Prev Med 2015;76:79-83.

22. Healy GN, Winkler EA, Brakenridge CL, et al. Accelerometer-derived sedentary and physical activity time in overweight/obese adults with type 2 diabetes: cross-sectional associations with cardiometabolic biomarkers. PLoS ONE 2015;10:e0119140.

23. Buman MP, Winkler EA, Kurka JM, et al. Reallocating time to sleep, sedentary behaviors, or active behaviors: associations with cardiovascular disease risk biomarkers, NHANES 2005-2006. Am J Epidemiol 2014;179:323-34.

24. Hamer M, Stamatakis E, Steptoe A. Effects of substituting sedentary time with physical activity on metabolic risk. Med Sci Sports Exerc 2014;46:1946-50.

25. Healy GN, Winkler EA, Owen N, et al. Replacing sitting time with standing or stepping: associations with cardio-metabolic risk biomarkers. Eur Heart J 2015;36:2643-9.

26. Yates T, Davies MJ, Henson J, et al. Walking away from type 2 diabetes: trial protocol of a cluster randomized controlled trial evaluating a structured education programme in those at high risk of developing type 2 diabetes. BMC Fam Pract 2012;13:46.

27. Yates T, Edwardson CL, Henson J, et al. Walking away from type 2 diabetes: a cluster randomized controlled trial. Diabet Med 2016. In press. doi: 10.1111/dme.13254

28. Gray LJ, Davies MJ, Hiles S, et al. Detection of impaired glucose regulation and/or type 2 diabetes mellitus, using primary care electronic data, in a multiethnic UK community setting. Diabetologia 2012:55:959-66.

29. Matthews DR, Hosker JP, Rudenski AS, et al. Homeostasis model assessment: insulin resistance and $\beta$-cell function from fasting plasma glucose and insulin concentrations in man. Diabetologia 1985;28:412-19.

30. DeFronzo RA, Matsuda M. Reduced time points to calculate the composite index. Diabetes Care 2010;33:e93-e0646.

31. Otten J, Ahrén B, Olsson T. Surrogate measures of insulin sensitivity vs the hyperinsulinaemic-euglycaemic clamp: a meta-analysis. Diabetologia 2014;57:1781-8. 
32. Muniyappa $\mathrm{R}$, Lee $\mathrm{S}$, Chen $\mathrm{H}$, et al. Current approaches for assessing insulin sensitivity and resistance in vivo: advantages, limitations, and appropriate usage. Am J Physiol Endocrinol Metab 2008:294:E15-26.

33. Abdul-Ghani MA, Tripathy D, DeFronzo RA. Contributions of beta-cell dysfunction and insulin resistance to the pathogenesis of impaired glucose tolerance and impaired fasting glucose. Diabetes Care 2006;29:1130-9.

34. Winkler EA, Bodicoat $\mathrm{DH}$, Healy $\mathrm{GN}$, et al. Identifying adults' valid waking wear time by automated estimation in activPAL data collected with a 24-hour wear protocol. Physiol Meas 2016;37:1653-68.

35. Mekary RA, Willett WC, Hu FB, et al. Isotemporal substitution paradigm for physical activity epidemiology and weight change. Am $J$ Epidemiol 2009;170:519-27.

36. Dunstan DW, Kingwell BA, Larsen R, et al. Breaking up prolonged sitting reduces postprandial glucose and insulin responses. Diabetes Care 2012;35:976-83.

37. Peddie MC, Bone JL, Rehrer NJ, et al. Breaking prolonged sitting reduces postprandial glycemia in healthy, normal-weight adults: a randomized crossover trial. Am J Clin Nutr 2013;98: 358-66.

38. Bailey DP, Locke CD. Breaking up prolonged sitting with light-intensity walking improves postprandial glycemia, but breaking up sitting with standing does not. J Sci Med Sport 2015;18: 294-8.

39. Aadahl M, Linneberg A, Møller TC, et al. Motivational counseling to reduce sitting time: a community-based randomized controlled trial in adults. Am J Prev Med 2014;47:576-86.

40. Kozey Keadle S, Lyden K, Staudenmayer J, et al. The independent and combined effects of exercise training and reducing sedentary behavior on cardiometabolic risk factors. Appl Physiol Nutr Metab 2014;39:770-80.

41. Richter EA, Hargreaves M. Exercise, GLUT4, and skeletal muscle glucose uptake. Physiol Rev 2013;93:993-1017.

42. Bergouignan A, Latouche C, Reddy-Luthmoodoo M, et al. Breaking up sedentary time modulates both the contraction-and insulin-stimulated glucose uptake pathways in skeletal muscle. In Diabetes 2015;64:A522-A522. 